http://jmscr.igmpublication.org/home/ ISSN (e)-2347-176x ISSN (p) 2455-0450 crossref DOI: https://dx.doi.org/10.18535/jmscr/v8i1.71

\title{
Changes in various ocular parameters in primary angle closure patients with cataract following phacoemulsification
}

\author{
Authors \\ Dr S. Walia ${ }^{1}$, Dr Awani Dubey ${ }^{2 *}$, Dr Neetu Kori ${ }^{3}$, Dr Manushree Gautam ${ }^{4}$ \\ ${ }^{1}$ Professor, Department of Ophthalmology, M.G.M. Medical College \& M.Y. Hospital, Indore (M.P.) \\ ${ }^{2}$ Resident Doctor, Department of Ophthalmology, Mahatma Gandhi Memorial Medical College, M.Y. \\ Hospital Indore (M.P.) 452001 \\ ${ }^{3}$ Associate Professor, Department of Ophthalmology, Mahatma Gandhi Memorial Medical College, M.Y. \\ Hospital Indore (M.P.) 452001 \\ ${ }^{4}$ Assistant Professor, Department of Ophthalmology, Mahatma Gandhi Memorial Medical College, M.Y. \\ Hospital Indore (M.P.) 452001 \\ *Corresponding Author \\ Dr Awani Dubey
}

\section{Abstract}

Purpose: To assess intraocular pressure changes after phacoemulsification and its correlation with various intra ocular parameters in angle closure patients

Materials and Methods: We studied correlation of various ocular parameters with angle closure and change in intraocular pressure following phacoemulsification in patients aged 55-95 years with IOP>22 $\mathrm{mm} \mathrm{Hg}$ on 2 or more occasions with angle closure on gonioscopy and cataract

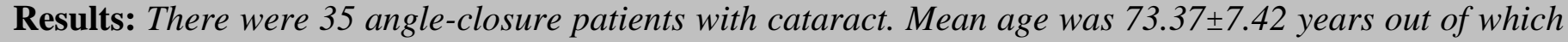
$37.15 \%$ were male and $62.85 \%$ were females, ,60\% had myopia, we found a negative correlation with anterior chamber depth ( $r=-0.468)$. We also found a positive correlation with, central corneal thickness $(r=0.259)$ and lens thickness $(r=0.064)$ Pre operative mean IOP was $27.60 \pm 6.03$ while post operatively at 1 week, 2 week, 4 week, 6 weeks, 3 months was 13.69 $\pm 2.88,12.23 \pm 2.70,12.56 \pm 2.51,12.11 \pm 2.42$ at and $12.40 \pm 2.74$ respectively. Pre operative gonioscopy scoring was $2.63 \pm 1.416$ while post operatively at 6 weeks and 3 months was $13.29 \pm 1.545$ and $13.71 \pm 1.416$ respectively. Only one patient required antiglaucoma medications post operatively.

Conclusion: Phacoemulsification cataract surgery leads to significant decrease in IOP and increase in $A C D$ in cataract patients with angle closure with peripheral anterior synechiae $<180$ degrees. Thick crystalline lens leads to angle closure through reduction of ACD and narrowing of angle. Thus cataract surgery may be a safe alternative to glaucoma surgery in angle closure patients and could shift the surgeon's approach in treatment of concurrent cataract and glaucoma.

Keywords: Cataract Surgery, Phacoemulsification, Intraocular Pressure, Angle Closure.

\section{Introduction}

Primary angle closure glaucoma (PACG) is estimated to affect 15 million people worldwide and is responsible for half of all glaucoma blindness $^{(\mathbf{1})}$. Prevalence of occludable angle in Asia is $10.2 \%{ }^{(2)} \mathrm{A}$ lens induced mechanism in the 
development of angle closure glaucoma has been suggested. A thick crystalline lens might lead to angle closure through reduction of anterior chamber depth and narrowing of the angle ${ }^{(3,)}$. Formosan $\mathbf{R}$ et al $\mathbf{2 0 0 8}^{(\mathbf{4})}$ demonstrated intraocular pressure reduction after cataract surgery.

.Many patients with glaucoma have concurrent cataracts and some studies by, Hodge WG, et al 1995, Ughade SN, et al $1998{ }^{(5,6)}$ have suggested that glaucoma itself is a risk factor for cataract development.

Bobrow JC 2008, Kass MA, et al 2002, ${ }^{(7,8)}$ suggested that glaucoma filtering procedures, peripheral iridotomy and some glaucoma medications increase the risk of cataract formation Historically, Heijl A, et al 2002, ${ }^{(9)}$ believed patients with moderate to advanced glaucoma with concurrent cataracts would have either a combined procedure or a two-stage surgery.

The purpose of this study is to evaluate efficacy of phacoemulsification surgery on reduction in IOP in primary angle closure patients and its correlation with intra ocular parameters

\section{Materials and Method}

The study protocol was approved by the institutional review committee and study was performed in accordance to the tenets of the Helsinki Declaration. A written informed voluntary consent was taken from all the study subjects. All patients underwent standard ocular examination protocol which included Visual acuity examination (UCVA,BCVA), Examination of anterior segment of eye by slit lamp oblique illumination, with grading of cataract by LOCS $3^{\text {rd }}$ grading system, Tonometry by applanation tonometer, standard posterior segment examination was carried out presence of any obstruction in lacrimal passage excluded by syringing, lens thickness by A scan, classification of primary angle closure as per ISGEO (International Society of Geographical and Epidemiologic Ophthalmology) (Table 1). Written informed consent was taken from all patients.

\section{Operative Procedure}

All surgeries were performed by a single surgeon Peribulbar, anesthesia was used. Pre operative mannitol was given in all patients. A temporal clear corneal incision was followed by injection of viscoelastic, continuous curvilinear capsulorrhexis, and standard phacoemulsification with placement of an intraocular lens in the posterior chamber. Wounds not found to be watertight were sutured with 10-0 nylon suture.

\section{Results}

35 patients were included in the study. Mean age was $73.37 \pm 7.42$ years, $22(62.85 \%)$ patients were female and $13(37.15 \%)$ patients were male. (Table 2)

$3(8.57 \%)$ patients had CCT of $<500$ micron, $5(14.28 \%)$ patients had CCT of $501-524$ micron, $10(28.57 \%)$ patients had CCT of 525-549 micron, 9(25.71\%) patients had CCT of 550-574 micron, $\& 8(22.85 \%)$ patients had CCT of $>574$ micron

We also found a positive correlation between pre op CCT and pre op IOP although it was not clinically significant $(\mathrm{p}=0.133, \mathrm{r}=0.259)$

Table 6 shows mean anterior chamber depth was $2.75 \pm 0.48 \mathrm{~mm} 22(62.85 \%)$ patients had preoperative anterior chamber depth between 2-2.99 mm $11(31.42 \%)$ patients had pre op ACD between $3-4 \mathrm{~mm}$ and in $2(5.714 \%)$ patients had pre op ACD of $<2 \mathrm{~mm}$. We also found a negative correlation between pre op IOP and pre op ACD which was statistically significant $(p=.005$ and $\mathrm{r}=-0.468$ )

Mean lens thickness in enrolled patients was 4.68 $\pm 0.47 \mathrm{~mm} \mathrm{3}(8.57 \%)$ patients had lens thickness of $<4 \mathrm{~mm}, 7(20 \%)$ patients had lens thickness between $4-4.5 \mathrm{~mm}, 19(54.28 \%)$ patients had lens thickness between 4.51 - 5mm \& 6(17.14\%) patients had $>5 \mathrm{~mm}$ of lens thickness We also found that there was a positive correlation between lens thickness and pre op IOP although it was not clinically significant $(\mathrm{p}=0.716, \mathrm{r}=$ 0.064) most of the patients had a drop of IOP of $>5 \mathrm{~mm} \mathrm{Hg}$ following phacoemulsification (Table 3) 
Table 4C shows mean IOP pre operatively and at various follow ups.

On applying Repeated Measure ANOVA with a Greenhouse- Geisser Assumed IOP was found to be statistically significantly different among the six groups. ( $F=144.151 ; \mathrm{p}=<0.0001)$ Post hoc tests using the Bonferroni correction was applied to determine difference between groups. IOP was significantly different between Pre op and Post op at the end of $1^{\text {st }}$ weeks $(\mathrm{p}=<0.0001)$.

In addition, IOP difference between Pre op and Post op values at 2 weeks was found to be statistically significant $(\mathrm{p}=<0.0001)$. Also, IOP difference between Preop and Post op values at 4 weeks was found to be statistically significant $(\mathrm{p}=<0.0001)$ and, IOP difference between Pre op and Post IOP 6 weeks values were found to be statistically significant $(\mathrm{p}=<0.0001)$. finally, IOP difference between Pre op and Post op values at 3 months was found to be statistically significant $(\mathrm{p}=<0.0001)$. (Table 4A, 4B,4D)
Mean pre-operative gonioscopy scoring was and $2.63 \pm 1.416$ Post operatively at 6 weeks gonioscopy scoring was $13.29 \pm 1.545$ and after 3 months was $13.71 \pm 1.690$ Pre operatively gonioscopy scoring was $0-4$ in $30(85.71 \%)$ patients and 5-8 in 5(14.28 \%) patients Post operatively it was 9-16 in all the patients.. We found that post operatively the gonioscopy scoring was increased (angles were open) and the result was found statistically significant $(\mathrm{p}<0.001)$ on applying ANNOVA TEST (Table 5)

Table 6 shows that 10 (28.57\%) patients had sub conjunctival haemorrhage, $4(11.42 \%)$ patients had corneal edema/striate keratitis, $2(5.71 \%)$ patients had floppy iris and $1(2.87 \%)$ patient had hyphaema post operatively and there were no cases with vitreous hemorrhage, macular edema, decentered IOL, endophthalmitis, pan ophthalmitis and expulsive choroidal hemorrhage

Table No. 1 International society geographic and epidemiological ophthalmology (ISGEO) classification of Primary angle closure

\begin{tabular}{|l|l|}
\hline Primary angle closure suspect (PACS) & ITC in 3 or more quadrants; No PAS, normal IOP, disc and field \\
\hline Primary angle closure ( PAC) & $\begin{array}{l}\text { ITC in } 3 \text { or more quadrants with either raised IOP and /or primary } \\
\text { PAS ;normal IOP ,disc and field }\end{array}$ \\
\hline Primary angle closure Glaucoma & $\begin{array}{l}\text { ITC in } 3 \text { or more quadrants, evidence of glaucomatous damage to } \\
\text { optic disc and field }\end{array}$ \\
\hline Acute primary angle closure & $\begin{array}{l}\text { Presence of at least } 2 \text { of the following symptoms: ocular or } \\
\text { periocular pain, nausea and/or vomiting, an antecedent history of } \\
\text { intermittent blurring of vision with halos. Presenting IOP }>21 \\
\text { mmHg and presence of at least } 3 \text { of the following signs: } \\
\text { conjunctival injection, corneal epithelial edema, mid dilated } \\
\text { unreactive pupil and shallow anterior chamber }\end{array}$ \\
\hline
\end{tabular}

Note: IOP-intraocular pressure, peripheral anterior synechiae: ITC - iridotrabecular contact

Table No.2: Age and Sex Distribution

\begin{tabular}{|l|c|c|c|c|c|c|}
\hline \multirow{2}{*}{ Age in years } & \multicolumn{2}{|c|}{ Male } & \multicolumn{2}{c|}{ Female } & \multicolumn{2}{c|}{ Total } \\
\cline { 2 - 7 } & No. & $\%$ & No. & $\%$ & No. & $\%$ \\
\hline $55-65$ & 0 & 0 & 3 & 8.5 & 3 & 8.5 \\
\hline $65.1-75$ & 8 & 22.85 & 12 & 34.28 & 20 & 57.14 \\
\hline$>75$ & 5 & 14.28 & 7 & 20 & 12 & 34.28 \\
\hline Total & 13 & 37.15 & 22 & 62.85 & 35 & 100 \\
\hline
\end{tabular}

Table No.3 Correlation of various pre op factors with pre op IOP

\begin{tabular}{|l|c|c|}
\hline Parameters & Mean pre operative & Correlation factor with IOP \\
\hline central corneal thickness & $522.57 \pm 49.32$ & $\mathrm{r}=0.259 ; \mathrm{p}=0.133$ \\
\hline Anterior chamber depth & $2.755 \pm 0.47$ & $\mathrm{r}=-0.468 ; \mathrm{p}=0.005$ \\
\hline Lens thickness & $4.68 \pm 0.47$ & $\mathrm{r}=0.064 ; \mathrm{p}=0.064$ \\
\hline
\end{tabular}


Table No 4A.: Pre-Op and Post Op Intra ocular Pressure

\begin{tabular}{|l|c|c|c|c|}
\hline \multirow{2}{*}{ IOP } & \multicolumn{2}{|c|}{ Pre-op } & \multicolumn{2}{c|}{ Post op } \\
\cline { 2 - 5 } & No of patients & Percentage & No of patients & Percentage \\
\hline$<20 \mathrm{~mm} \mathrm{Hg}$ & 0 & 0 & 35 & 100 \\
\hline $20-24.99 \mathrm{mmHg}$ & 17 & 48.57 & 0 & 0 \\
\hline $25-28 \mathrm{~mm} \mathrm{Hg}$ & 8 & 22.85 & 0 & 0 \\
\hline$>28 \mathrm{mmHg}$ & 10 & 28.57 & 0 & 0 \\
\hline
\end{tabular}

Table No 4B.: Change in intra ocular pressure following phacoemulsification surgery

\begin{tabular}{|l|c|c|}
\hline Intra ocular pressure & No. of patients & Percentage \\
\hline $1-3 \mathrm{~mm}$ & 0 & 0 \\
\hline $3-5 \mathrm{~mm}$ & 1 & 2.8 \\
\hline$>5 \mathrm{~mm}$ & 34 & 97.14 \\
\hline
\end{tabular}

Table No 4C.

\begin{tabular}{|l|l|}
\hline INTRA OCULAR PRESSURE & MEAN \pm SD \\
\hline Pre IOP & $27.60 \pm 6.03$ \\
\hline Post IOP 1 week & $13.69 \pm 2.88$ \\
\hline IOP 2 week & $12.23 \pm 2.70$ \\
\hline IOP 4 week & $12.56 \pm 2.51$ \\
\hline IOP 6 week & $12.11 \pm 2.42$ \\
\hline IOP 3 month & $12.40 \pm 2.74$ \\
\hline
\end{tabular}

Table No.4D

\begin{tabular}{|c|c|c|c|c|c|}
\hline \multirow[b]{2}{*}{ Group } & \multirow[b]{2}{*}{ Group } & \multirow[b]{2}{*}{$\begin{array}{c}\text { Mean } \\
\text { Difference }\end{array}$} & \multicolumn{2}{|c|}{ 95\% Confidence interval } & \multirow[b]{2}{*}{ p- value } \\
\hline & & & $\begin{array}{c}\text { Lower } \\
\text { limit }\end{array}$ & $\begin{array}{c}\text { Upper } \\
\text { limit }\end{array}$ & \\
\hline Pre IOP & 1 week & .906 & 10.781 & 17.030 & 0.0001 \\
\hline Pre IOP & Post IOP 2 week & 15 & 10. & 19.050 & $<0.0001$ \\
\hline Pre IOP & Post IOP 4 week & 15.043 & 11.423 & 18.663 & $<0.0001$ \\
\hline Pre IOP & Post IOP 6 week & 15.486 & 11.917 & 19.055 & $<0.0001$ \\
\hline Pre IOP & Post IOP 3 month & 15.200 & 11.562 & 18.838 & $<0.0001$ \\
\hline
\end{tabular}

Table No. 5: Change in Gonioscopic Scoring following phacoemulsification surgery

\begin{tabular}{|l|c|c|c|c|}
\hline $\begin{array}{l}\text { Gonioscopic } \\
\text { scoring }\end{array}$ & Pre-op & Percent & Post op & Percent \\
\hline $0-4$ & 30 & 85.71 & 0 & 0 \\
\hline $5-8$ & 5 & 14.28 & 0 & 0 \\
\hline $9-16$ & 0 & 0 & 35 & 100 \\
\hline
\end{tabular}

Table No.6: Intra-Operative and Post-Operative Complications

\begin{tabular}{|l|c|c|}
\hline \multirow{2}{*}{ Complication } & \multicolumn{2}{|c|}{ Total } \\
\cline { 2 - 3 } & No. & Percentage \\
\hline Subconjunctival haemorrhage & 10 & 28.57 \\
\hline Corneal edema/Striate keratitis & 4 & 11.42 \\
\hline Vitreous haemorrhage & 0 & 0 \\
\hline Macular edema & 0 & 0 \\
\hline Decentered IOL & 0 & 0 \\
\hline Floppy Iris & 2 & 5.71 \\
\hline Hyphaema & 1 & 2.87 \\
\hline Endophthalmitis & 0 & 0 \\
\hline pan ophthalmitis & 0 & 0 \\
\hline Expulsive choroidal haemorrhage & 0 & 0 \\
\hline
\end{tabular}




\section{Discussion}

In the present study on "Changes in various ocular parameters in primary angle closure patients with cataract following phacoemulsification" 35 Primary Angle Closure patients were included

In this study a large proportion of patients were aged 55-95 with a female preponderance Sakai et al. in $1996{ }^{(\mathbf{1 0})}$ suggested that anterior chamber depth and volume gradually decrease throughout life. In 1996 they analysed anterior chamber changes and demonstrated a depth decrease of $0.21 \mathrm{~mm}$ and volume decrease $1.9 \mathrm{ml}$ over 10 years; in concert, these changes contribute to angle narrowing and increase the likelihood of PAS among the elderly.

Quigley \& Broman 2006 ${ }^{(11)}$ concluded that risk of PACG among women is approximately 3 times higher than in men. This, too, is likely the result of anatomical and mechanical differences between male and female eyes..

In this study we also found a positive correlation between pre op CCT and pre op IOP although it was not clinically significant $(p=0.133, r=0.259$ Shah et al ${ }^{(\mathbf{1 2})}$ reported significantly higher CCT in PACG eyes as compared to POAG and normal eyes. Considering these findings, it can be hypothesized that a thicker cornea may have a contributory effect on angle occludability, that is, a thicker CCT may be associated with a thick peripheral cornea and thus a more crowded angle. We found a negative correlation between pre op IOP and pre op ACD which was statistically significant $(p=.005$ and $r=-0.468$ ), Similar to our study association of ACD with PACG has been suggested by Tomlinson and Leighton,

Tomlinson and Leighton et al ${ }^{(\mathbf{1 3})} \mathrm{did}$ a study in 108 patients and concluded that in the presence of a thick, anteriorly sited lens, angle-closure is the more likely to occur if the corneal diameter and corneal height are small.

We found that there was a positive correlation between lens thickness and pre op IOP although it was not clinically significant $(\mathrm{p}=0.716, \mathrm{r}=$ 0.064), Similar association of LT with PACG was demonstrated by Saxena $S$ et al
Saxena $\mathbf{S}$ et al ${ }^{(\mathbf{1 4 )}}$ a tertiary care centre-based casecontrol study, 70 patients and equal number of controls were investigated to analyse the strength of association and predictability of anterior chamber depth (ACD) and lens thickness (LT) in the disease and demonstrated a statistically significant association $(\mathrm{P}<0.01)$ of $\mathrm{PACG}$ and lens thickness

Inour study mean pre op IOP was $27.6 \pm 6.03$,Pre op IOP was $20-24.99 \mathrm{mmHg}$ in 17 patients, 25$28 \mathrm{mmHg}$ in 8 patients and $>28 \mathrm{mmHg}$ in 10 patients which was $<20 \mathrm{mmHg}$ in all post op patients

most of the patients had a drop of IOP of $>5 \mathrm{~mm}$ $\mathrm{Hg}$ following phacoemulsification. Bradford and James $^{(15)}$ in their retrospective analysis of 55 eyes of 55 patients who had clear corneal phacoemulsification with follow up of at least 3 years demonstrated that cataract removal by clear cornea phacoemulsification in glaucoma patients, glaucoma suspects, and normal patients results in a small but significant decrease in IOP that is sustained at 3 years and a mean of 5 years in all group. Jimmy Lai, and Clement ${ }^{(\mathbf{1 6})}$ in their study of twenty-one primary angle-closure glaucoma eyes of 21 patients concluded that in primary angle-closure glaucoma patients with co-existing cataract, cataract extraction alone (by phacoemulsification) can significantly reduce both intraocular pressure and the requirement for glaucoma drugs

We found that post operatively the gonioscopy scoring was increased (angles were open) and the result was found statistically significant ( $p$ $<0.001$ ) on applying ANNOVA TEST

Shan C. Lin et $\mathbf{a l}^{(\mathbf{1 7 )}}$ in their study Predictors of Intraocular Pressure After Phacoemulsification in Primary Open-Angle Glaucoma Eyes with Wide Versus Narrower Angles included 66 eyes of 40 glaucoma patients and concluded that in POAG eyes, cataract surgery lowered IOP to a greater degree in the narrower-angle group than in the wide-angle group, and parameters relating to iris thickness and area, as well as lens vault, were correlated with IOP reduction. 
Inour study 10(28.57\%) patients had sub conjunctival haemorrhage, $4(11.42 \%)$ patients had corneal edema/striate keratitis, $2(5.71 \%)$ patients had floppy iris and $1(2.87 \%)$ patient had hyphaema post operatively

And there were no cases with vitreous hemorrhage, macular edema, decentered IOL, endophthalmitis, pan ophthalmitis and expulsive choroidal hemorrhage Intraocular surgery in patients with angle closure is more challenging than in open angle because of shallow AC, potential presence os posterior synechiae, The intra and post operative complications were reported by Nolan W $2006^{(18)}$ and Khokhar et al $\mathbf{2 0 0 2}^{(\mathbf{1 9 )}}$ are as follows iris trauma, posterior capsule rupture, thermal burns at the wound, and post operative inflammation

\section{Conclusion}

Based on the available data, it seems reasonable to state that for patients with PAC without peripheral anterior synechiae, phacoemulsification alone results in a modest decrease in IOP and seems to be relatively safe, Phacoemulsification and PCIOL implantation for PAC patients may offer successful IOP control, and maintenance of improved vision. Phacoemulsification eliminates pupillary block, widens the angle to lessen angle crowding thus reducing the iridotrabecular proximity, and is the only treatment alternative that reduces if not corrects the responsible anatomic predisposition to angle closure. Also parameters like, central corneal thickness, anterior chamber depth, lens thickness and pre operative intraocular pressure are correlated to angle closure. These findings can guide ophthalmologist in their selection of cataract surgery as a potential management option.

There is no conflict of interest in our study. It was approved by ethics and scientific review committee MGM medical college \& MY hospital, Indore for which approval number is IRB00007879-. All patients included in the study had given written informed consent.

\section{References}

1. Quigley H.A., Broman A.T. The number of people with glaucoma worldwide in 2010 and 2020. $\mathrm{Br} \mathrm{J}$ Ophthalmol. 2006;90:262-267

2. Aung T., Ang L.P., Chan S.-P., Chew P.T. Acute primary angle-closure: long-term intraocular pressure outcome in Asian eyes. Am J Ophthalmol. 2001;131:7-12.

3. George R., Paul P., Baskaran M. Ocular biometry in occludable angles and angle closure glaucoma: a population based survey. Br J Ophthalmol. 2003;87:399402.

4. Foroozan R, Levkovitch-Verbin H, HabotWilner Z, Burla N. Cataract Surgery and Intraocular Pressure. Ophthalmology 2008;115:104-8.

5. Hodge WG, Whitcher JP, Satariano W. Risk factors for agerelated cataracts. Epidemiol Rev 1995;17:336-46.

6. Ughade SN, Zodpey SP, Khanolkar VA. Risk factors for cataract: a case control study. Indian J Ophthalmol 1998;46:221-7.

7. Bobrow JC. Factors Influencing Cataract Formation After Nd: YAG Laser Peripheral Iridotomy. Trans Am Ophthalmol Soc 2008;106:93-7.

8. Kass MA, Heuer DK, Higginbotham EJ, Johnson CA, Keltner JL, Miller JP, et al. The Ocular Hypertension Treatment Study a randomized trial determines that topical ocular hypotensive medication delays or prevents the onset of primary open-angle glaucoma. Arch Ophthalmol 2002;120: 701-13.

9. Heijl A, Leske MC, Bengtsson B, Hyman $\mathrm{L}$, Bengtsson B, Hussein $\mathrm{M}$, et al. Reduction of intraocular pressure and glaucoma progression: results from the Early Manifest Glaucoma Trial. Arch Ophthalmol 2002;120:1268-79.146.

10. Sakai H, Sato T, Koibuchi H, Hayakawa K,Yamakawa R \&Nagataki S. Anteriorchamber dimensions in patients 
with angle-closure glaucoma measured by an anterior eyesegment analysis system. Nihon Ganka Gak-kai Zasshi 1996;100: 546-550

11. Quigley HA \& Broman AT. The number ofpeople with glaucoma worldwide in 2010 and2020. Br J Ophthalmol 2006;90: 262-267.

12. Shah S, Chatterjee A, Mathai M, Kelly SP, Kwartz J, Henson D, et al. Relationship between corneal thickness and measured intraocular pressure in a general ophthalmology clinic. 1999;106:21542160

13. Tomlinson A and Leighton DA. Ocular dimensions and the heredity of angleclosure glaucoma. $\mathrm{Br} \mathrm{J}$ Ophthal $\neg$ mol. 57:475-486, 1973.

14. Saxena S, Agrawal P K, Pratap V B, Nath R. Anterior chamber depth and lens thickness in primary angle-closure glaucoma : A case-control study. Indian J Ophthalmol 1993;41:71-3

15. Angle Closure Glaucoma Three and Five Year Changes in Intraocular Pressures After Clear Corneal Phacoemulsification in Open Angle Glaucoma Patients, Glaucoma Suspects, and Normal Patients Bradford Shingleton;James Pasternack; James Hung; Mark O'Donoghue;

16. Lai, Jimmy \&Tham, Clement \& Chan, Jonathan. (2006). The Clinical Outcomes of Cataract Extraction by Phacoemulsification in Eyes With Primary Angle-Closure Glaucoma (PACG) and CoExisting Cataract. Journal of glaucoma. 15. 47-52.

10.1097/01.ijg.0000196619.34368.0a.
17. Shan C. Lin, Marisse Masis, Travis C. Porco, Louis R. Pasquale Trans Am Ophthalmol Soc. 2017 Aug; 115: T6. Published online 2017 Oct 23.Refractive Surgery. J Cataract Refract Surg 2013; 39:673-679; erratum, 971

18. Nolan W Lens extraction in primary angle closure.British journal of ophthalmology 2006:90;1

19. Khokhar S, Sindhu N, Pangtey MS Phacoemulsification in filtered chronic angle closure eyes Clinical \& Experimental ophthalmology 2002;30; 256-260 